\title{
Identification of Mepenzolate Derivatives With Long-Acting Bronchodilatory Activity
}

\begin{abstract}
Ken-Ichiro Tanaka't, Naoki Yamakawa ${ }^{2 \dagger}$, Yasunobu Yamashita ${ }^{3}$, Teita Asano ${ }^{4}$, Yuki Kanda ${ }^{1}$, Ayaka Takafuji', Masahiro Kawahara', Mitsuko Takenaga ${ }^{4}$, Yoshifumi Fukunishi ${ }^{3}$ and Tohru Mizushima ${ }^{5 *}$
\end{abstract}

\begin{abstract}
'Research Institute of Pharmaceutical Sciences, Faculty of Pharmacy, Musashino University, Nishi-Tokyo, Japan, ${ }^{2}$ School of Pharmacy, Shujitsu University, Okayama, Japan, ${ }^{3}$ Molecular Profiling Research Center for Drug Discovery, National Institute of Advanced Industrial Science and Technology, Tokyo, Japan, ${ }^{4}$ Institute of Medical Science, School of Medicine, St. Marianna University, Kawasaki, Japan, ${ }^{5}$ LTT Bio-Pharma Co., Ltd., Tokyo, Japan
\end{abstract}

\section{OPEN ACCESS}

Edited by:

Weien Yuan,

Shanghai Jiao Tong University, China

Reviewed by:

Thiago J. Borges,

Universidade La Salle-Canoas, Brazil

Michela De Bellis,

Università degli Studi di Bari Aldo

Moro, Italy

Erzsébet Bartolák-Suki,

Boston University, United States

*Correspondence:

Tohru Mizushima

t.mizushima@ltt.co.jp

${ }^{t}$ These authors have contributed equally to this work.

Specialty section:

This article was submitted to Translational Pharmacology, a section of the journal

Frontiers in Pharmacology

Received: 28 September 2017 Accepted: 26 March 2018

Published: 10 April 2018

Citation:

Tanaka K-I, Yamakawa N, Yamashita Y, Asano T, Kanda Y,

Takafuji A, Kawahara M,

Takenaga M, Fukunishi Y and Mizushima T (2018) Identification of Mepenzolate Derivatives With Long-Acting Bronchodilatory Activity.

Front. Pharmacol. 9:344.

doi: 10.3389/fphar.2018.00344
The standard treatment for chronic obstructive pulmonary disease is a combination of anti-inflammatory drugs and bronchodilators. We recently found that mepenzolate bromide (MP), an antagonist for human muscarinic $M 3$ receptor $\left(\mathrm{hM}_{3} \mathrm{R}\right)$, has both anti-inflammatory and short-acting bronchodilatory activities. To obtain MP derivatives with longer-lasting bronchodilatory activity, we synthesized hybrid compounds based on MP and two other muscarinic antagonists with long-acting bronchodilatory activity glycopyrronium bromide (GC) and aclidinium bromide (AD). Of these three synthesized hybrid compounds (MP-GC, GC-MP, MP-AD) and MP, MP-AD showed the highest affinity for $\mathrm{hM}_{3} \mathrm{R}$ and had the longest lasting bronchodilatory activity, which was equivalent to that of $\mathbf{G C}$ and $\mathbf{A D}$. Both MP-GC and MP-AD exhibited an antiinflammatory effect equivalent to that of MP, whereas, in line with $\mathbf{G C}$ and $\mathbf{A D}$, GC-MP did not show this effect. We also confirmed that administration of MP-AD suppressed elastase-induced pulmonary emphysema in a mouse model. These findings provide important information about the structure-activity relationship of MP for both bronchodilatory and anti-inflammatory activities.

Keywords: chronic obstructive pulmonary disease, anti-inflammatory, long-acting bronchodilatory activity, mepenzolate

\section{INTRODUCTION}

Chronic obstructive pulmonary disease (COPD) is a serious health problem and the world's fourth leading cause of death (Mannino and Kiriz, 2006). This disease state is defined by a progressive and not fully reversible airflow limitation and an abnormal inflammatory response (Rabe et al., 2007; Vestbo et al., 2013; Vogelmeier et al., 2017). For the clinical treatment of COPD, it is therefore important not only to improve airflow limitations by inducing bronchodilation, but also to hinder disease progression by suppressing inflammatory responses.

The standard treatment for COPD is to use bronchodilators such as $\beta 2$-agonists and muscarinic receptor antagonists, with this approach being effective in overcoming airflow limitations (Barnes and Stockley, 2005; Vestbo et al., 2013; Vogelmeier et al., 2017). Short-acting $\beta 2$-agonists (SABAs) and muscarinic antagonists (SAMAs) were previously used for COPD treatment; however, longacting $\beta 2$-agonists (LABAs) and muscarinic antagonists [LAMAs, of which tiotropium bromide 
(TP), glycopyrronium bromide (GC), and aclidinium bromide (AD) are common examples] have shown superior efficacy over the short-acting bronchodilators for the treatment of COPD (Vestbo et al., 2013; Vogelmeier et al., 2017). Thus, LABAs and LAMAs (or combinations of the two) are now used as first-line drugs for COPD treatment.

On the other hand, the inflammatory responses associated with COPD are generally treated with steroids; however, their impact on reducing disease progression and mortality (Barnes and Stockley, 2005; Calverley et al., 2007; Tashkin et al., 2008) is attenuated because COPD-associated inflammation often shows resistance to steroid treatment (Alsaeedi et al., 2002; Calverley et al., 2007). Thus, it is important for new types of antiinflammatory compounds to be developed for the treatment of COPD.

Based on the aforementioned, we previously screened a library of approved medicines to identify compounds capable of preventing elastase-induced pulmonary emphysema in mice (an animal model of COPD), and selected mepenzolate bromide (MP) (Tanaka et al., 2013), which is an orally administered muscarinic receptor antagonist used to treat gastrointestinal disorders (Long and Keasling, 1954; Buckley et al., 1957; Chen, 1959). We showed that MP not only exerts an anti-inflammatory effect via a muscarinic receptor-independent mechanism, but also possesses a short-acting bronchodilatory effect via a muscarinic receptor-dependent mechanism [via its binding to human muscarinic M3 receptor $\left(\mathrm{hM}_{3} \mathrm{R}\right)$ ] (Tanaka et al., 2013, 2014; Kurotsu et al., 2014). The anti-inflammatory activity of MP, which was more potent than that of steroids (Tanaka et al., 2012, 2013), is mediated via a decreased level of reactive oxygen species (ROS) in the lung due to the inhibition of NADPH oxidase activity and the induction of superoxide dismutase (SOD) and glutathione-S-transferase (GST) expression (Tanaka et al., 2013).

In the present study, we examined MP derivatives that have both anti-inflammatory and longer-acting bronchodilatory activities, as these could be beneficial for the treatment of COPD. To this end, we synthesized hybrid compounds from MP and long-acting muscarinic antagonists (GC and AD) and identified one compound that showed both a longer duration of bronchodilatory activity (equivalent to GC and AD) together with anti-inflammatory properties consistent with those of MP.

\section{MATERIALS AND METHODS}

\section{Chemistry}

Muscarinic M3 receptor antagonists were purchased from commercial sources; mepenzolate bromide (MP) was from Sigma-Aldrich (St. Louis, MO, United States); tiotropium bromide (TP) and glycopyrronium bromide (GC) were from Tokyo Chemical Industry, Co., Ltd. (Tokyo, Japan); aclidinium bromide (AD) was from Toronto Research Chemicals (Toronto, ON, Canada). All other solvents and reagents for organic syntheses were purchased from Tokyo Chemical Industry, Co., Ltd. (Tokyo, Japan) or Wako Pure Chemical Industries (Tokyo, Japan) and used without further purification. The precursor of hybrid compound (pre-Hyb) was synthesized by the condensation of carboxylic acid (BA or CA) and amino-alcohol (PR, PP, or QC). The each final quaternary salt of hybrid compounds (MP-GC, GC-MP, MP-AD) was prepared as described previously (Yamashita et al., 2014), with some modifications (see below). Column chromatography was performed using Silica gel 60N (Kanto Chemical, Co., Tokyo, Japan).

Melting point (mp) data were recorded on Yanaco MPJ3 micro-melting point apparatus. ${ }^{1} \mathrm{H}-\mathrm{NMR}$ spectra and ${ }^{13} \mathrm{C}$ NMR spectra were measured at 400 and $100 \mathrm{MHz}$, respectively, on a VARIAN 400-MR spectrometer. High resolution mass spectra were detected with an ESI-TOF mass spectrometer (Bruker MicroTOF, Bruker, Bremen, Germany) in the positive mode. HPLC data were recorded on a Waters 2695 Alliance separation module and a Waters 2996 photodiode array detector (Waters, Milford, MA, United States) with a reverse-phase column (TSKgel Super-ODS, $150 \mathrm{~mm} \times 4.6 \mathrm{~mm}, 2 \mu \mathrm{m}$, Tosoh, Co., Tokyo, Japan). $\mathrm{CH}_{3} \mathrm{CN} / 20 \mathrm{mM} \mathrm{K \textrm {K } _ { 2 }} \mathrm{PO}_{4}$ buffer (3:7) was used as the mobile phase at a flow rate of $0.3 \mathrm{ml} / \mathrm{min}$, with detection performed at an optical density of $210 \mathrm{~nm}$.

\section{General Procedure for the Preparation of pre-Hyb}

To a solution of 2-alkyl-2-hydroxy-2-phenylacetic acid (BA or CA) (1.0 eq.) in DMF, carbonyldiimidazole (1.6 eq.) was added and the mixture was stirred for $15 \mathrm{~min}$ at room temperature. A solution of $N$-alkyl amino alcohol (PR, PP, or QC) (1.2 eq.) in $\mathrm{DMF}$ was added dropwise into the mixture at $80^{\circ} \mathrm{C}$ and the mixture was stirred for $18 \mathrm{~h}$ at that temperature. The reaction was quenched with $\mathrm{H}_{2} \mathrm{O}$ at room temperature and organic materials were extracted with EtOAc. The combined extract was washed with brine, dried over $\mathrm{Na}_{2} \mathrm{SO}_{4}$ and concentrated in vacuo. The residue was then applied to a short silica gel column, eluted with EtOAc and concentrated in vacuo to give title compound (pre-Hyb), which was used for the next step without further purification.

\section{( \pm )-3-(2-Hydroxy-2,2-diphenylacetoxy)-1,1- dimethylpyrrolidinium Bromide (MP-GC)}

$2.0 \mathrm{~g}(8.7 \mathrm{mmol})$ of benzilic acid (BA) and $1.3 \mathrm{~mL}(11 \mathrm{mmol})$ of 1-methylpyrrolidin-3-ol (PR) were used to give pre-Hyb. To a solution of pre-Hyb $(2.2 \mathrm{~g}, 7.0 \mathrm{mmol})$ in $\mathrm{CH}_{3} \mathrm{CN}(12 \mathrm{~mL})$, $\mathrm{CH}_{3} \mathrm{Br}(2.0 \mathrm{M}$ in THF, $18 \mathrm{~mL})$ was added and stirred for $5 \mathrm{~h}$ at room temperature. The precipitate was filtered off and the filtrate re-crystallized with $\mathrm{CH}_{3} \mathrm{CN}$ and diethyl ether to give the title compound as a white solid (2.0 g, 69\% 2 steps). mp: $211-212^{\circ} \mathrm{C}$; ${ }^{1} \mathrm{H}-\mathrm{NMR}$ (DMSO-d6): $\delta=7.29-7.38(\mathrm{~m}, 10 \mathrm{H}), 6.81(\mathrm{~s}, 1 \mathrm{H}), 5.51$ (brs, $1 \mathrm{H}), 3.84-3.89(\mathrm{~m}, 1 \mathrm{H}), 3.52-3.70(\mathrm{~m}, 3 \mathrm{H}), 3.6(\mathrm{~s}, 3 \mathrm{H})$, $2.93(\mathrm{~s}, 3 \mathrm{H}), 2.62-2.74(\mathrm{~m}, 1 \mathrm{H}), 2.08-2.14(\mathrm{~m}, 1 \mathrm{H}) ;{ }^{13} \mathrm{C}-\mathrm{NMR}$ (DMSO- $d 6$ ): $d=172.3,142.9,127.9,127.7,127.0,80.6,73.3,69.3$, 64.0, 52.7, 51.9, 40.2, 38.9, 29.9; HRMS: calcd. for $\mathrm{C}_{20} \mathrm{H}_{24} \mathrm{NO}_{3}$ $\left(\mathrm{M}^{+}\right): 326.1751$; found: $\mathrm{m} / \mathrm{z}=326.1755$; HPLC: $t_{\mathrm{R}}(\mathrm{min})=3.12$ (98\%). This is a known compound, but its spectrum data are not covered by patents or non-patent literature documents. 
( \pm )-3-(2-Cyclopentyl-2-hydroxy-2-phenylacetoxy)1,1-dimethylpiperidinium Bromide (GC-MP)

$1.5 \mathrm{~g}(6.8 \mathrm{mmol})$ of 2-cyclopentyl-2-hydroxy-2-phenylacetic acid (CA) and $1.0 \mathrm{~mL}$ (8.1 mmol) of 1-methylpiperidin-3ol (PP) were used to give pre-Hyb. To a solution of preHyb (0.41 g, $1.3 \mathrm{mmol})$ in $\mathrm{CH}_{3} \mathrm{CN}(5 \mathrm{~mL}), \mathrm{CH}_{3} \mathrm{Br}(2.0 \mathrm{M}$ in THF, $6.4 \mathrm{~mL}$ ) was added and stirred for $5 \mathrm{~h}$ at room temperature. The precipitate was filtered off and the filtrate re-crystallized with $\mathrm{CH}_{3} \mathrm{CN}$ and diethyl ether to give the title compound as a white solid $(0.38 \mathrm{~g}, 22 \% 2$ steps $)$. mp: $164-$ $165^{\circ} \mathrm{C}$; ${ }^{1} \mathrm{H}-\mathrm{NMR}$ (DMSO-d6): $\delta=7.56-7.59(\mathrm{~d}, J=7.5$, $2 \mathrm{H}), 7.25-7.37$ (m, 3H), 5.14 (brs, $1 \mathrm{H}), 3.37-3.62(\mathrm{~m}, 4 \mathrm{H})$, 2.89-3.06 (m, 7H), 1.23-1.79 (m, 12H); ${ }^{13} \mathrm{C}-\mathrm{NMR}$ (DMSO-d6): $\delta=173.0,142.2,142.7,128.0,127.3,125.7,79.3,66.1,61.5$, $60.8,46.4,40.1,38.9,26.6,26.0,25.6,25.4,16.4$; HRMS calcd. for $\mathrm{C}_{20} \mathrm{H}_{30} \mathrm{NO}_{3}\left(\mathrm{M}^{+}\right)$: 332.2220; found: $\mathrm{m} / \mathrm{z}=332.2224$; HPLC: $t_{\mathrm{R}}(\min )=4.94(98 \%)$. This is a known compound, but its spectrum data are not covered by patents or non-patent literature documents.

\section{(土)-3-(2-Hydroxy-2,2-diphenylacetoxy)-1-(3- phenoxypropyl)-1-azoniabicyclo[2.2.2]octane Bromide (MP-AD)}

$1.6 \mathrm{~g}(0.60 \mathrm{mmol})$ of benzilic acid (BA) and $1.0 \mathrm{~g}(7.9 \mathrm{mmol})$ of quinuclidin-3-ol (QC) were used to give pre-Hyb. To a solution of pre-Hyb $(0.10 \mathrm{~g}, 0.30 \mathrm{mmol})$ in 1,4 -dioxane $(5 \mathrm{~mL})$ (3-bromopropoxy)benzene $(0.11 \mathrm{~g}, 11 \mathrm{mmol})$ was added and stirred for 6 days at room temperature. The precipitate was filtered off and the filtrate re-crystallized with $\mathrm{CH}_{3} \mathrm{CN}$ and diethyl ether to give the title compound as a white solid (50 mg, 30\% 2 steps). mp: $177-178^{\circ} \mathrm{C} ;{ }^{1} \mathrm{H}-\mathrm{NMR}$ (DMSO-d6): $\delta=7.23-$ $7.42(\mathrm{~m}, 12 \mathrm{H}), 6.86-6.89(\mathrm{~m}, 3 \mathrm{H}), 6.78(\mathrm{~s}, 1 \mathrm{H}), 5.22$ (brs, $1 \mathrm{H}), 3.94-4.04(\mathrm{~m}, 2 \mathrm{H}), 3.85-3.88(\mathrm{~m}, 1 \mathrm{H}), 3.25-3.44(\mathrm{~m}, 5 \mathrm{H})$, 3.01-3.07 (m, 1H), 1.45-2.25 (m, 7H); ${ }^{13} \mathrm{C}-\mathrm{NMR}$ (DMSO-d6): $\delta=173.0,158.6,143.6,143.5,130.1,128.5,128.4,128.2,127.6$, $127.5,121.5,115.0,81.3,69.1,65.1,61.1,60.0,54.3,53.2,24.0$, 22.2, 20.9, 18.1; HRMS calcd. for $\mathrm{C}_{30} \mathrm{H}_{34} \mathrm{NO}_{4}\left(\mathrm{M}^{+}\right)$: 472.2482; found: $\mathrm{m} / \mathrm{z}=472.2488$; HPLC: $t_{\mathrm{R}}(\mathrm{min})=9.26(99 \%)$. This is a known compound whose ${ }^{1} \mathrm{H}-\mathrm{NMR}$ spectrum was similar to that previously reported as (R)-MP-GC (Yamashita et al., 2014).

\section{Chemicals}

Porcine pancreatic elastase (PPE) and methacholine chloride (methacholine) were obtained from Sigma-Aldrich (St. Louis, MO, United States). Novo-Heparin for injection was from Mochida Pharmaceutical, Co. (Tokyo, Japan). Chloral hydrate was from Nacalai Tesque (Kyoto, Japan). Diff-Quik was from Sysmex, Co. (Kobe, Japan). Formalin neutral buffer solution was from WAKO Pure Chemicals (Tokyo, Japan). Mayer's hematoxylin, $1 \%$ eosin alcohol solution and malinol were from MUTO Pure Chemicals (Tokyo, Japan).

\section{Animals}

ICR mice (6-7 weeks old, male) were purchased from Charles River (Yokohama, Japan). The experiments and procedures described here were carried out in accordance with the Guide for the Care and Use of Laboratory Animals as adopted and promulgated by the National Institutes of Health, and were approved by the Animal Care Committee of Musashino University (Approval NOs. 16004 and 17006).

\section{Treatment of Mice With PPE and Each Drug}

Mice maintained under anesthesia with isoflurane were administered one intratracheal bolus of PPE (15 or $20 \mathrm{U} / \mathrm{kg}$ ), MP $(3.8,37.5 \mu \mathrm{g} / \mathrm{kg}), \mathbf{T P}(8.4 \mu \mathrm{g} / \mathrm{kg}), \mathbf{G C}(7.1,35.5 \mu \mathrm{g} / \mathrm{kg}), \mathbf{A D}(10.1$, $50.4 \mu \mathrm{g} / \mathrm{kg})$, MP-GC $(3.6,36.2 \mu \mathrm{g} / \mathrm{kg})$, GC-MP $(3.7,36.8 \mu \mathrm{g} / \mathrm{kg})$, and MP-AD $(4.9,49.3 \mu \mathrm{g} / \mathrm{kg})$ in $0.9 \% \mathrm{NaCl}$ via micropipette (P200). For control mice, $0.9 \% \mathrm{NaCl}$ alone was administered by the same procedure.

Figure 3; MP, GC, AD, MP-AD, MP-GC, or GC-MP were administered intratracheally. After $1,24,48$, or $72 \mathrm{~h}$, mice were exposed to nebulized methacholine 5 times and airway resistance was determined after each methacholine challenge.

Figure 4 and Table 2; MP, TP, GC, AD, MP-AD, MPGC, and GC-MP were administered intratracheally once only. After $1 \mathrm{~h}$, mice were treated with or without (control) PPE (20 U/kg) once only. Six (Figure 4) or twenty-four (Table 2) hours after the PPE administration, BALF was prepared and the total cell number and the number of neutrophils were determined.

Figure 5; MP-AD was administered intratracheally once daily for 16 days (from day 0 to day 15). $1 \mathrm{~h}$ after the first administration, mice were treated with or without (control) PPE (15 U/kg) once only on day 0. 21 days after the PPE administration, lung mechanics was monitored, and sections of pulmonary tissue were prepared.

\section{Preparation of Bronchoalveolar Lavage Fluid (BALF) and Cell Count Method}

BALF was collected from mice by cannulating the trachea and lavaging the lung with $1 \mathrm{ml}$ of sterile PBS containing $50 \mathrm{U} / \mathrm{ml}$ heparin (2 times). About $1.8 \mathrm{ml}$ of BALF was routinely recovered from each animal. The total cell number in the BALF was counted using a hemocytometer and a manual counter. Cells were stained with Diff-Quik reagents after centrifugation with Cytospin ${ }^{\circledR} 4$ (Thermo Electron Corporation, Waltham, MA, United States), and differential counts of more than 50 inflammatory cells were done in each of four or more separate sections of smear using fluorescence microscopy (Olympus DP71). The ratio of number of neutrophils to total cell number was determined by counting the number of neutrophils. This cell counting was conducted by an investigator blinded to the study protocol.

\section{Measurement of Lung Mechanics and Airway Resistance}

Lung mechanics and airway resistance were monitored with a computer-controlled small-animal ventilator (FlexiVent, SCIREQ, Montreal, QC, Canada), as described previously (Shalaby et al., 2010; Tanaka et al., 2012). Mice were anesthetized 
with chloral hydrate $(500 \mathrm{mg} / \mathrm{kg})$, a tracheotomy was performed, and an $8 \mathrm{~mm}$ section of metallic tube was inserted into the trachea. Mice were mechanically ventilated at a rate of 150 breaths/min, using a tidal volume of $8.7 \mathrm{ml} / \mathrm{kg}$ and a positive end-expiratory pressure of $2-3 \mathrm{cmH}_{2} \mathrm{O}$.

Total respiratory system compliance was measured by the snapshot. All data were analyzed using FlexiVent software (version 5.3; SCIREQ, Montreal, QC, Canada).

Mice were exposed to nebulized methacholine $(5 \mathrm{mg} / \mathrm{ml})$ five times for $20 \mathrm{~s}$ with a $40 \mathrm{~s}$ interval, and airway resistance was measured after each methacholine challenge by the snapshot technique. All data were analyzed using FlexiVent software.

\section{Histopathological Analysis}

Twenty one days after PPE treatment, mice were euthanized with an excess of isoflurane. Lung tissue samples were fixed in $10 \%$ formalin neutral buffer solution for $24 \mathrm{~h}$ at a pressure of $25 \mathrm{cmH}_{2} \mathrm{O}$, and then embedded in paraffin before being cut into $4 \mu \mathrm{m}$-thick sections. Sections were stained first with Mayer's hematoxylin and then with $1 \%$ eosin alcohol

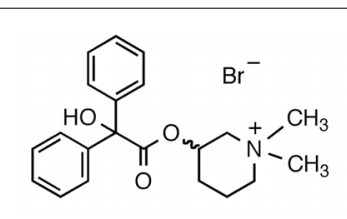

Mepenzolate (MP)<smiles>C[N+]1(C)CC[C@@H](OC(=O)C(c2ccccc2)(C2CCCC2)C2CCCC2)C1</smiles>

Glycopyrronium (GC)

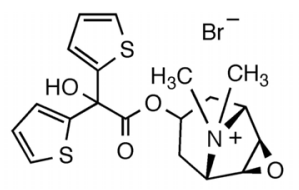

Tiotropium (TP)

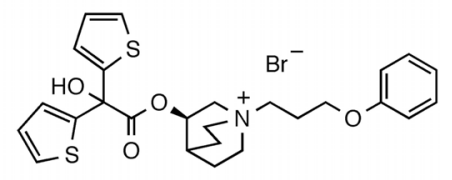

Aclidinium

(AD)
FIGURE 1 | Structure of clinically-used muscarinic antagonists.

TABLE 1 | Binding of compounds to hM2R or hM3R.

\begin{tabular}{lcc}
\hline \multirow{2}{*}{ Compound } & \multicolumn{2}{c}{$\boldsymbol{K i}$ (nM) } \\
\cline { 2 - 3 } & $\mathbf{h M}_{\mathbf{3}} \mathbf{R}$ & $\mathbf{h M}_{\mathbf{2}} \mathbf{R}$ \\
\hline Mepenzolate (MP) & 4.6 & 1.8 \\
Tiotropium (TP) & 0.22 & 0.64 \\
Glycopyrronium (GC) & 0.7 & 1.0 \\
Aclidinium (AD) & 0.34 & 0.39 \\
MP-GC & 1.1 & 0.79 \\
GC-MP & 1.2 & 0.53 \\
MP-AD & 0.72 & 0.64 \\
\hline
\end{tabular}

Membrane fractions prepared from $\mathrm{CHO}-\mathrm{K} 1$ cells expressing hM2R or hM3R were incubated with $2 \mathrm{nM}$ [ ${ }^{3} \mathrm{HINMS}(85.5 \mathrm{Ci} / \mathrm{mmol})$ in the presence of each compound. A range of concentrations $\left(10^{-11}\right.$ to $\left.10^{-6} \mathrm{M}\right)$ for each compound was tested in triplicate to generate competitive binding curves to determine Ki values. The shown value is an average of at least two independent experiments.
TABLE 2 | Effect of intratracheal administration of compounds on PPE-induced inflammatory responses.

\begin{tabular}{lcc}
\hline & Total cells $\left(\times \mathbf{1 0}^{\mathbf{5}}\right.$ cells) & Neutrophils $\left(\mathbf{\times 1 \mathbf { 1 0 } ^ { \mathbf { 5 } } \text { cells } )}\right.$ \\
\hline Control & $1.26 \pm 0.25$ & $0.12 \pm 0.07$ \\
$\mathrm{PPE}$ & $9.66 \pm 0.54^{* *}$ & $7.46 \pm 0.57^{* *}$ \\
$\mathrm{PPE}+\mathrm{MP}(37.5 \mu \mathrm{g} / \mathrm{kg})$ & $6.30 \pm 0.90^{\# \#}$ & $4.11 \pm 0.68^{\# \#}$ \\
$\mathrm{PPE}+\mathrm{TP}(8.4 \mu \mathrm{g} / \mathrm{kg})$ & $10.00 \pm 1.27$ & $6.81 \pm 1.03$ \\
$\mathrm{PPE}+\mathrm{TP}(42.1 \mu \mathrm{g} / \mathrm{kg})$ & $10.05 \pm 0.57$ & $7.31 \pm 0.22$ \\
$\mathrm{PPE}+\mathrm{GC}(7.1 \mu \mathrm{g} / \mathrm{kg})$ & $10.20 \pm 0.93$ & $7.34 \pm 0.92$ \\
$\mathrm{PPE}+\mathrm{GC}(35.5 \mu \mathrm{g} / \mathrm{kg})$ & $9.09 \pm 1.09$ & $6.25 \pm 0.83$ \\
$\mathrm{PPE}+\mathrm{AD}(10.1 \mu \mathrm{g} / \mathrm{kg})$ & $11.88 \pm 2.01$ & $9.06 \pm 1.63$ \\
$\mathrm{PPE}+\mathrm{AD}(50.4 \mu \mathrm{g} / \mathrm{kg})$ & $9.75 \pm 1.12$ & $6.86 \pm 0.88$
\end{tabular}

Mice were treated with or without (control) PPE (20 U/kg) once only on day 0. The indicated doses $(\mu \mathrm{g} / \mathrm{kg})$ of each compound were administered intratracheally once only on day 0. Twenty-four hours after the PPE administration, BALF was prepared and the total cell number and the number of neutrophils were determined as described in Section "Materials and Methods." Values represent mean \pm SEM ( $n=4-8)$. ${ }^{* *} P<0.01$ (versus control); ${ }^{\#} P<0.01$ (versus PPE only). Data are representative of two independent experiments.

solution (H\&E staining). Samples were mounted with malinol and scanned using a NanoZoomer-XR digital slide scanner (Hamamatsu Photonics, Shizuoka, Japan). All images were analyzed using NDP.view2 software (Hamamatsu Photonics, Shizuoka, Japan).

To determine the mean linear intercept (MLI) (an indicator of airspace enlargement), 20 lines $(800 \mu \mathrm{m})$ were drawn randomly on the image of a section and intersection points with alveolar walls were counted to determine the MLI, as described previously (Weibel, 1963). This morphometric analysis was conducted by an investigator blinded to the study protocol.

\section{Filter-Binding Assay}

The filter-binding assay was performed as described previously (Yamashita et al., 2014), with some modifications. Membrane fractions prepared from Chinese Hamster Ovary (CHO)-K1 cells expressing human muscarinic $\mathrm{M} 2$ receptor $\left(\mathrm{hM}_{2} \mathrm{R}\right)$ or $\mathrm{hM}_{3} \mathrm{R}$ (Membrane Target Systems, Perkin-Elmer Life and Analytical Sciences, Boston, MA, United States; protein concentration, $8 \mu \mathrm{g} /$ well) were incubated with $2 \mathrm{nM}\left[{ }^{3} \mathrm{H}\right] \mathrm{NMS}$ ( $N$-methyl$\left[{ }^{3} \mathrm{H}\right]$-scopolamine methylchloride $)(85.5 \mathrm{Ci} / \mathrm{mmol})$ at room temperature for $2 \mathrm{~h}$ in $200 \mu \mathrm{L}$ PBS in the presence of each compound. A range of concentrations $\left(10^{-11}\right.$ to $\left.10^{-6} \mathrm{M}\right)$ for each compound was tested in triplicate to generate competitive binding curves. Non-specific binding was determined in the presence of atropine $(2.5 \mu \mathrm{M})$. The samples were passed through a GF/C filter (Filtermat A, PerkinElmer Life and Analytical Sciences, Boston, MA, United States) pre-incubated for $1 \mathrm{~h}$ with $1.0 \%$ polyethylenimine, and washed four times with ice-cold wash buffer [50 mM Tris/ $\mathrm{HCl}(\mathrm{pH} 7.4), 100 \mathrm{mM}$ $\mathrm{NaCl}, 0.05 \%$ Tween-80]. Filters were then dried for $30 \mathrm{~min}$ before attachment to a MeltiLex A melt-on scintillation sheet (PerkinElmer Life and Analytical Sciences, Boston, MA, United States). The radioactivity remaining on the filter was monitored with a MicroBeta Trilux microplate scintillation counter (PerkinElmer Life and Analytical Sciences, Boston, MA, 


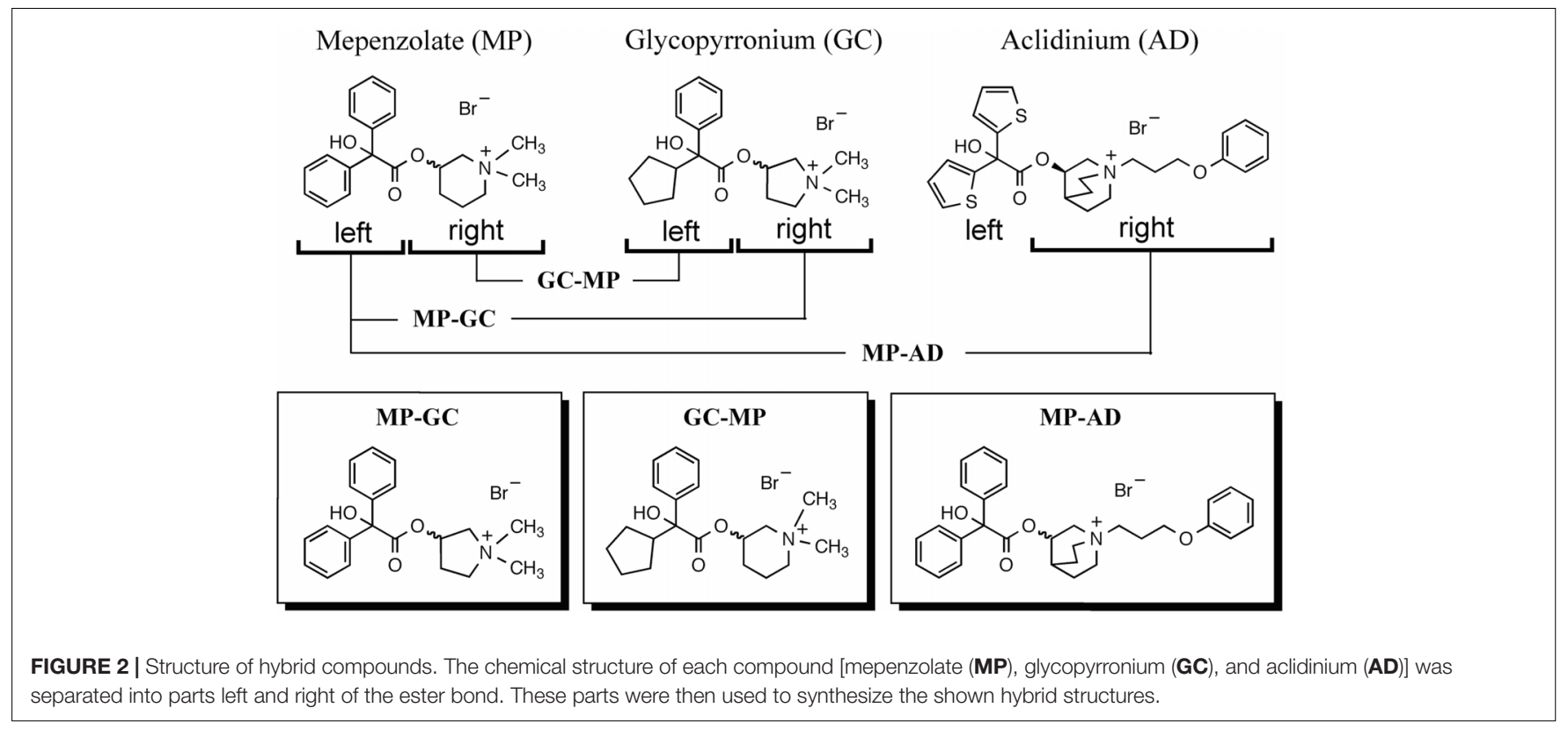

(a): $\mathrm{R}_{2}=$

United States). Affinities at equilibrium were determined as antagonist dissociation constant $(K \mathrm{i})$ values after correcting the experimentally determined $\mathrm{IC}_{50}$ values with the experimentally determined $K d$ value of NMS for $h_{2} \mathrm{R}$ or $\mathrm{hM}_{3} \mathrm{R}$ and the concentration of NMS, as described previously (Yamashita et al., 2014). Shown values are an average of at least two independent experiments. The Ki value was obtained from three independent curves. All curve-fitting procedures were performed using Prism (GraphPad Software, Inc., San Diego, CA, United States).

\section{Statistical Analysis}

All values are expressed as the mean \pm SEM. Homoscedasticity of data were verified by Levene test, then, data were examined 
using one-way ANOVA followed by the Tukey test or GamesHowell test for unpaired results was used to evaluate differences between three or more groups. Differences were considered to be statistically significant for values of $P<0.05$.

\section{RESULTS}

\section{Affinity for $\mathrm{hM}_{3} \mathrm{R}$ and Anti-inflammatory Activities of MP, TP, GC, and AD}

We first compared the binding of $\mathbf{M P}, \mathbf{T P}, \mathrm{GC}$, and $\mathrm{AD}$ to $\mathrm{hM}_{3} \mathrm{R}$ and $\mathrm{hM}_{2} \mathrm{R}$ (Figure 1). The binding affinity of each compound to each receptor was determined by carrying out $\left[{ }^{3} \mathrm{H}\right] \mathrm{NMS}$ displacement studies on each receptor. A higher $K$ i value means a lower affinity for $h_{3} \mathrm{R}$, because $K \mathrm{i}$ value is related to the concentration of each compound that causes $50 \%$ inhibition of NMS-binding to $\mathrm{hM}_{3} \mathrm{R}$. As shown in Table 1, MP showed the highest $K$ i value (by a factor of at least five compared with TP, GC, and AD), thus indicating it had the lowest affinity for $h M_{3} R$. Similar results were observed for $\mathrm{hM}_{2} \mathrm{R}$ (Table $\mathbf{1}$ ).

The total number of leucocytes and the individual number of neutrophils in BALF are indicators of pulmonary inflammatory responses; these increased after PPE treatment in a manner that could be partially suppressed by the simultaneous intratracheal administration of MP (Table 2), as described previously (Tanaka et al., 2013, 2014). Because compared to neutrophils, neither the macrophage nor eosinophil number was so apparently increased in BALF after PPE treatment (Tanaka et al., 2013, 2014), we did not count them here. As none of TP, GC, and AD showed anti-inflammatory activity equivalent to that of MP (Table 2), we attempted to identify MP derivatives that had an affinity for $\mathrm{hM}_{3} \mathrm{R}$ equivalent to that of TP, GC, and AD and an antiinflammatory activity equivalent to that of MP.

\section{Synthesis of Hybrid Compounds and Their Affinities for $\mathrm{hM}_{3} R$}

We synthesized hybrid compounds based on MP and LAMAs used in the clinical setting (GC and AD). The structures of MP and these LAMAs were separated into two parts with a view to synthesizing hybrid compounds by substitution of each of the parts (Figure 2). We synthesized mepenzolateglycopyrronium (MP-GC), glycopyrronium-mepenzolate (GCMP) and mepenzolate-aclidinium (MP-AD) (Figure 2). The synthetic route for these compounds are outlined in Scheme $\mathbf{1 .}$ First, the ester compound (pre-Hyb) was synthesized by the condensation of an appropriate carboxylic acid (BA or CA) and aminoalcohol (PR, PP, or QC). The precursor of target compound (pre-Hyb) was quaternized with the appropriate methyl bromide or phenoxy alkyl bromide to give target compounds (MP-GC, GC-MP, and MP-AD). These compounds are known and were identified by their melting points, NMR spectra, and mass spectra. On the other hand, we could not synthesize a hybrid compound based on aclidiniummepenzolate.

As shown in Table 1, all of the hybrid compounds had a lower $\mathrm{Ki}$ value for $\mathrm{hM}_{3} \mathrm{R}$ than MP. Of the target compounds, MP-AD
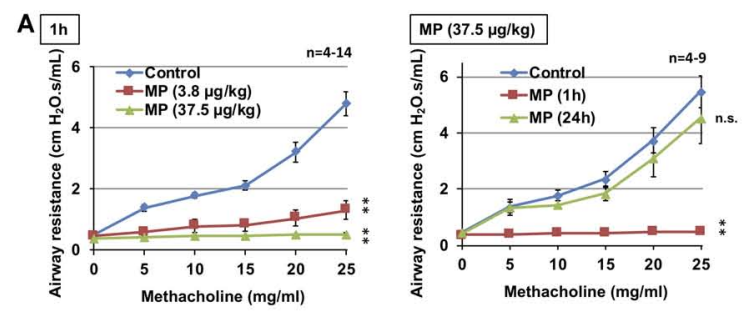

B
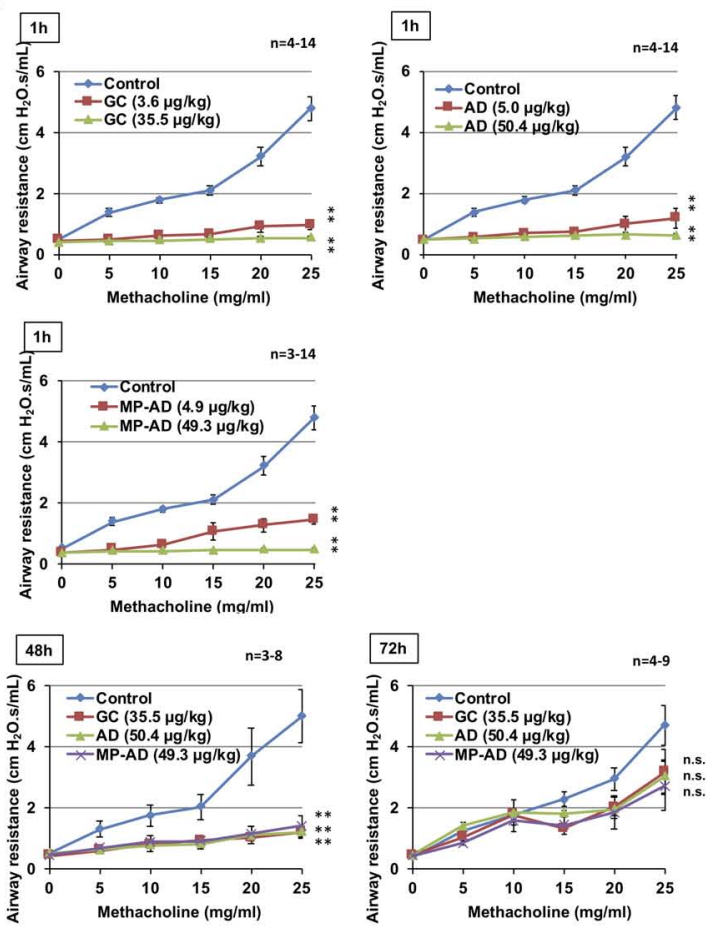

C
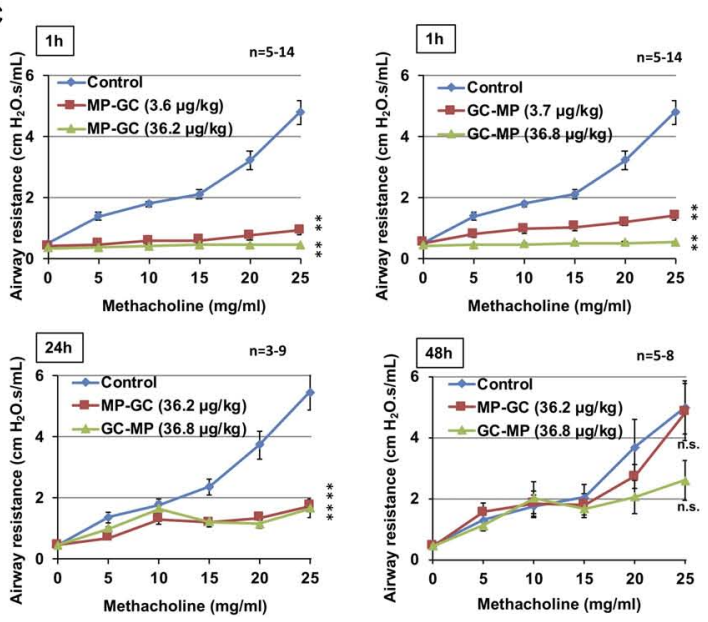

FIGURE 3 | Effect of compounds on methacholine-induced airway constriction. Indicated doses of MP (A), GC, AD, and MP-AD (B) or MP-GC or GC-MP (C) were administered intratracheally. After the indicated period, mice were exposed to nebulized methacholine 5 times and airway resistance was determined after each methacholine challenge as described in Section "Materials and Methods." Values represent mean \pm SEM. ${ }^{*} P<0.05$;

${ }^{* *} P<0.01$; n.s., not significant. The control data is the same in all graphs. Data are representative of two independent experiments. 


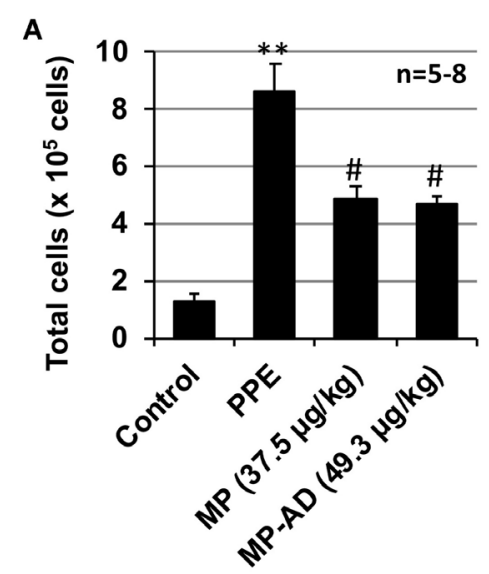

B

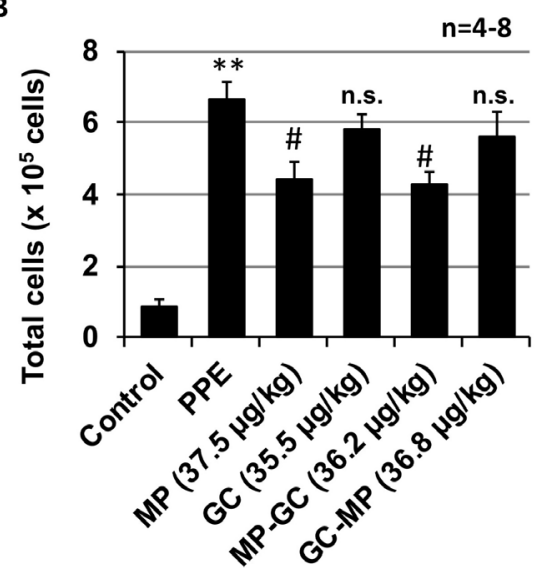

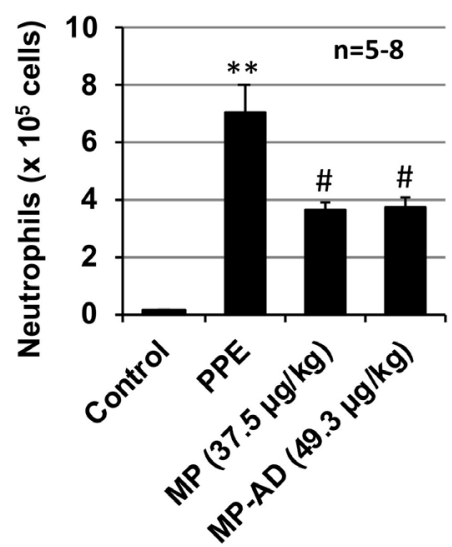

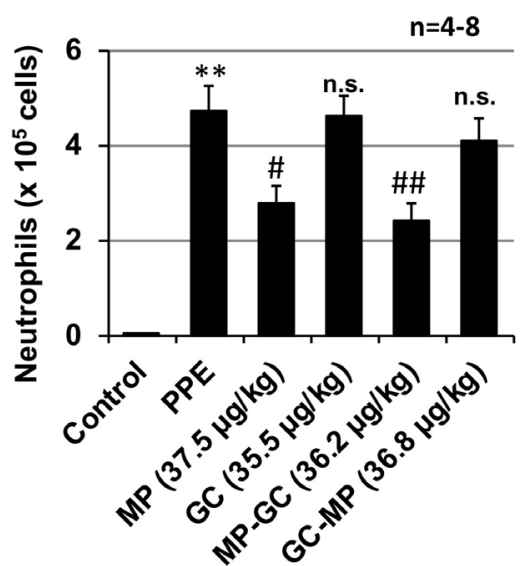

FIGURE 4 | Effect of compounds on PPE-induced inflammatory responses. Mice were treated with or without (control) PPE (20 U/kg) once only on day 0. The indicated doses $(\mu \mathrm{g} / \mathrm{kg}$ ) of MP and MP-AD (A) or MP, GC, MP-GC, or GC-MP (B) were administered intratracheally once only. Six hours after the PPE administration, BALF was prepared and the total cell number and the number of neutrophils were determined as described in Section "Materials and Methods." Values represent mean \pm SEM. ${ }^{* *} P<0.01$ (versus control); ${ }^{\#} P<0.05$, ${ }^{\# \#} P<0.01$ (versus PPE only); n.s., not significant. Data are representative of two independent experiments.

showed the lowest $K$ i value for $\mathrm{hM}_{3} \mathrm{R}$ (highest affinity for $\mathrm{hM}_{3} \mathrm{R}$ ), while GC-MP showed the lowest $K$ i value for $\mathrm{hM}_{2} \mathrm{R}$.

\section{Bronchodilation Activities of Hybrid Compounds}

As shown in Figure 3A, the intratracheal administration of MP induced bronchodilation in a dose-dependent manner, which is consistent with our previously reported findings (Tanaka et al., 2013, 2014). We also confirmed that the bronchodilatory activity of MP disappeared within $24 \mathrm{~h}$ (Figure 3A), suggesting that its effects were short-acting.

We then compared these results with the duration of bronchodilatory activity of GC, AD, and MP-AD. As shown in Figure 3B, these compounds all exhibited dose-dependent bronchodilatory activity within $1 \mathrm{~h}$ of their administration. Compared to baseline, significantly increased bronchodilation (reduced airway resistance) was observed $48 \mathrm{~h}$ (but not $72 \mathrm{~h}$ ) after the administration, suggesting that MP-AD has a long-lasting bronchodilatory activity, similar to that of GC and AD. We also examined the duration of bronchodilation for MP-GC and GCMP. Both of these compounds showed bronchodilatory activity at 1 and $24 \mathrm{~h}$, but not at $48 \mathrm{~h}$ (Figure 3C), suggesting that MPGC and GC-MP exhibit bronchodilatory activity intermediate to that of MP and MP-AD.

\section{Anti-inflammatory and Anti-emphysemic Activities of Hybrid Compounds}

As shown in Figure 4A, the anti-inflammatory activity of MPAD was similar to that of MP. We also found that MP-GC exhibited anti-inflammatory activity, but as for GC, GC-MP did not (Figure 4B). These results suggest that the double phenyl rings in $\mathbf{M P}$ are important for its anti-inflammatory activity.

We next examined the effect of the long-term (up to 15 days) administration of MP-AD on PPE-induced lung injury. Histopathological analysis revealed that while PPE administration damaged the alveolar walls and increased MLI, this effect could be partially suppressed by the administration of MP-AD (Figures 5A,B). We could not find any adverse effects 

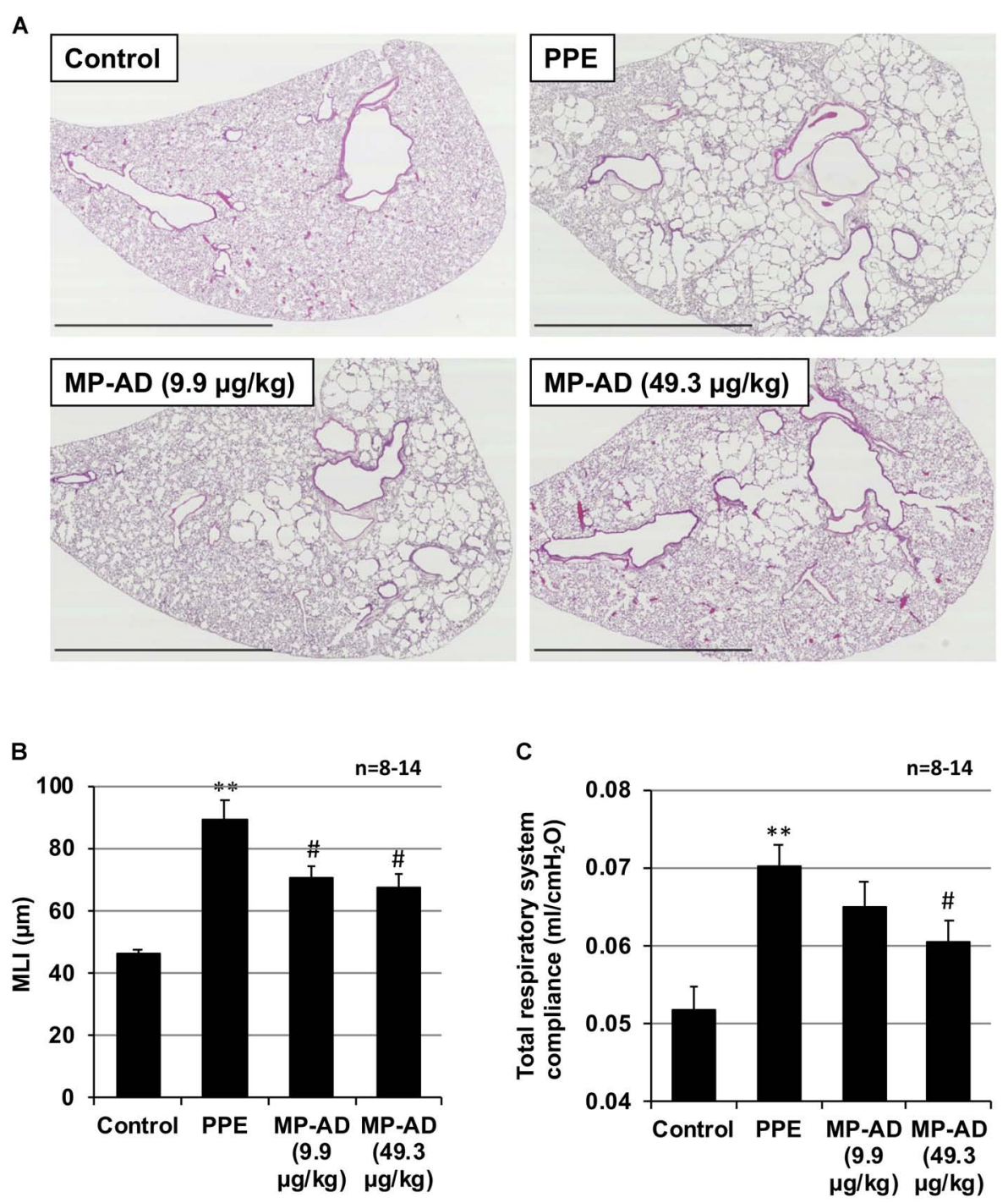

FIGURE 5 | Effect of MP-AD on PPE-induced pulmonary damage. Mice were treated with or without (control) PPE (15 U/kg) once only on day 0. The indicated doses of MP-AD were administered intratracheally once daily for 16 days (from day 0 to day 15). Sections of pulmonary tissue were prepared on day 21 and subjected to histopathological examination (H\&E staining) (scale bar: $2.5 \mathrm{~mm}$ ). (A) Airspace size was estimated by determining the MLI as described in Section "Materials and Methods." (B) Total respiratory system compliance was determined on day 21 as described in Section "Materials and Methods." (C) Values represent mean \pm SEM. ${ }^{* *} P<0.01$ (versus control); ${ }^{*} P<0.05$ (versus PPE only). Data are representative of two independent experiments.

(such as decrease in body weight or behavior abnormalities) in mice subjected to the long-term administration of MP-AD. Treatment of mice with PPE increased total respiratory system compliance (Figure 5C), as described previously (Hamakawa et al., 2011). We here found that treatment of mice with MP-AD restored total respiratory system compliance (Figure 5C). Based on these results, we suggest that MP-AD suppresses PPE-induced emphysema through its anti-inflammatory activity.

\section{DISCUSSION}

To obtain MP derivatives with longer-acting bronchodilatory activity, we synthesized hybrid compounds based on MP and
GC or AD. Among the compounds identified (MP-GC, GC-MP, and MP-AD), MP-AD showed the highest affinity for $\mathrm{hM}_{3} \mathrm{R}$ and the longest bronchodilatory activity. It should be noted that the duration of bronchodilation associated with MP-AD is equivalent to that of GC and AD, which are clinically used LAMAs. Based on these results, we speculate that the $N$-substituted 3-quinuclidinyl ester of $\mathrm{AD}$ is important for its long-acting bronchodilatory properties. On the other hand, both MP-GC and MP-AD showed anti-inflammatory effects similar to MP, whereas GC-MP, like GC and AD, did not exhibit this effect. Based on these results, we speculate that the double phenyl rings in MP are important for its anti-inflammatory activity. Our findings thus provide important information concerning the structure-activity relationship for MP, which underlies its bronchodilatory and anti-inflammatory 
activities. We consider that in silico drug design should be done for this target, because such trial for other diseases was successfully done for other studies (Corbo et al., 2007; De Luca et al., 2012). Such structure-activity investigation may also help to identify compounds with better toxicological profile avoiding off target effects (De Bellis et al., 2017).

As for the mechanism underlying these effects, the results from this study support the notion that the bronchodilatory effect is mediated through an antagonistic action toward $\mathrm{hM}_{3} \mathrm{R}$. Concerning the anti-inflammatory effects seen here, we previously showed that MP decreases ROS levels in the lung by inhibiting NADPH oxidase activity and by inducing the expression of SOD and GST, both of which are endogenous anti-oxidants (Tanaka et al., 2013). Furthermore, we previously described inhibitory effects of MP on nuclear factor- $\kappa \mathrm{B}$ and histone deacetylase 2, both of which are involved in the pathogenesis of COPD (Tanaka et al., 2013). Although we did not examine the effect of MP-AD on these inflammation-related proteins, a similar mechanism may underlie the anti-inflammatory properties of MP-AD. In order to confirm this, immunohistochemical experiments would be useful.

We measured airway resistance in mice exposed to nebulized methacholine, which is the most representative method for monitoring bronchodilatory effects (Ather et al., 2016; Murad et al., 2017). Although this method is convenient, it seems to be an asthmatic-like condition rather than COPD-like condition. Therefore, the effect of each drug on airway resistance should be examined in COPD animal model in future. Furthermore, in emphysema, the most important parameter is a compliance of pulmonary alveolus or total respiratory system. The compliance correlates best with lung structure (structural parameters) (Hamakawa et al., 2011). We here showed that treatment of mice with PPE increased total respiratory system compliance and that treatment of mice

\section{REFERENCES}

Alsaeedi, A., Sin, D. D., and McAlister, F. A. (2002). The effects of inhaled corticosteroids in chronic obstructive pulmonary disease: a systematic review of randomized placebo-controlled trials. Am. J. Med. 113, 59-65. doi: 10.1016/ S0002-9343(02)01143-9

Ather, J. L., Chung, M., Hoyt, L. R., Randall, M. J., Georgsdottir, A., Daphtary, N. A., et al. (2016). Weight loss decreases inherent and allergic methacholine hyperresponsiveness in mouse models of diet-induced obese asthma. Am. J. Respir. Cell Mol. Biol. 55, 176-187. doi: 10.1165/rcmb.20160070OC

Barnes, P. J., and Stockley, R. A. (2005). COPD: current therapeutic interventions and future approaches. Eur. Respir. J. 25, 1084-1106. doi: 10.1183/09031936.05. 00139104

Buckley, J. P., De, F. J., and Reif, E. C. (1957). The comparative antispasmodic activity of N-methyl-3-piperidyl diphenylglycolate methobromide (JB-340) and atropine sulfate. J. Am. Pharm. Assoc. Am. Pharm. Assoc. 46, 592-594. doi: $10.1002 /$ jps.3030461007

Calverley, P. M., Anderson, J. A., Celli, B., Ferguson, G. T., Jenkins, C., Jones, P. W., et al. (2007). Salmeterol and fluticasone propionate and survival in chronic obstructive pulmonary disease. N. Engl. J. Med. 356, 775-789. doi: 10.1056/NEJMoa063070

Chen, J. Y. (1959). Antispasmodic activity of JB-340 (N-methyl-3-piperidyldiphenylglycolate methobromide) with special reference to its relative selective with MP-AD restored total respiratory system compliance (Figure 5C).

In this study, we used intratracheal administration of each drug, because this method is convenient for experiments. However, it is possible that the compound does not distribute evenly through this method (Tanaka et al., 2010; Sato et al., 2015). The patchy appearance of airspace enlargement on the histological section following treatment with MP-AD may be explained by this uneven distribution of the drug. Thus, we should examine the distribution of this drug in the lung after intratracheal administration in future.

We also confirmed here that MP-AD suppressed elastaseinduced pulmonary damage and emphysema in a COPD mouse model. Taken together, we propose that MP-AD could serve as a new drug candidate for the treatment of COPD, given its long-lasting bronchodilatory and anti-inflammatory activity.

\section{AUTHOR CONTRIBUTIONS}

K-IT, NY, YY, YF, and TM: participated in research design. K-IT, NY, YY, TA, YK, and AT: conducted experiments. MK, MT, and YF: contributed new reagents or analytic tools. K-IT, NY, YY, TA, and TM: performed data analysis. K-IT, NY, YY, TA, YK, AT, MK, MT, YF, and TM: wrote or contributed to the writing of the manuscript.

\section{FUNDING}

This work was supported by Grants-in-Aid for Scientific Research from the Ministry of Health, Labour and Welfare of Japan. This research was also supported by the Suzuken Memorial Foundation, the Pharmacological Research Foundation Tokyo, and the Takeda Science Foundation.

action on the sphincter of Oddi, colon and urinary bladder of the dog. Arch. Int. Pharmacodyn. Ther. 121, 78-84.

Corbo, F., Franchini, C., Lentini, G., Muraglia, M., Ghelardini, C., Matucci, R., et al. (2007). Synthesis and biological evaluation of chiral alpha-aminoanilides with central antinociceptive activity. J. Med. Chem. 50, 1907-1915. doi: 10.1021/ jm061078e

De Bellis, M., Carbonara, R., Roussel, J., Farinato, A., Massari, A., Pierno, S., et al. (2017). Increased sodium channel use-dependent inhibition by a new potent analogue of tocainide greatly enhances in vivo antimyotonic activity. Neuropharmacology 113(Pt A), 206-216. doi: 10.1016/j.neuropharm.2016. 10.013

De Luca, A., De Bellis, M., Corbo, F., Franchini, C., Muraglia, M., Catalano, A., et al. (2012). Searching for novel anti-myotonic agents: pharmacophore requirement for use-dependent block of skeletal muscle sodium channels by N-benzylated cyclic derivatives of tocainide. Neuromuscul. Disord. 22, 56-65. doi: 10.1016/j. nmd.2011.07.001

Hamakawa, H., Bartolak-Suki, E., Parameswaran, H., Majumdar, A., Lutchen, K. R., and Suki, B. (2011). Structure-function relations in an elastase-induced mouse model of emphysema. Am. J. Respir. Cell Mol. Biol. 45, 517-524. doi: 10.1165/ rcmb.2010-04730C

Kurotsu, S., Tanaka, K., Niino, T., Asano, T., Sugizaki, T., Azuma, A., et al. (2014). Ameliorative effect of mepenzolate bromide against pulmonary fibrosis. J. Pharmacol. Exp. Ther. 350, 79-88. doi: 10.1124/jpet.114. 213009 
Long, J. P., and Keasling, H. H. (1954). The comparative anticholinergic activity of a series of derivatives of 3-hydroxy piperidine. J. Am. Pharm. Assoc. Am. Pharm. Assoc. 43, 616-619. doi: 10.1002/jps.3030431013

Mannino, D. M., and Kiriz, V. A. (2006). Changing the burden of COPD mortality. Int. J. Chron. Obstruct. Pulmon. Dis. 1, 219-233.

Murad, H. A., Habib, H. S., Rafeeq, M. M., Sulaiman, M. I., Abdulrahman, A. S., and Khabaz, M. N. (2017). Co-inhalation of roflumilast, rather than formoterol, with fluticasone more effectively improves asthma in asthmatic mice. Exp. Biol. Med. 242, 516-526. doi: 10.1177/1535370216685006

Rabe, K. F., Hurd, S., Anzueto, A., Barnes, P. J., Buist, S. A., Calverley, P., et al. (2007). Global strategy for the diagnosis, management, and prevention of chronic obstructive pulmonary disease: GOLD executive summary. Am. J. Respir. Crit. Care Med. 176, 532-555. doi: 10.1164/rccm.200703-456SO

Sato, S., Bartolak-Suki, E., Parameswaran, H., Hamakawa, H., and Suki, B. (2015). Scale dependence of structure-function relationship in the emphysematous mouse lung. Front. Physiol. 6:146. doi: 10.3389/fphys.2015.00146

Shalaby, K. H., Gold, L. G., Schuessler, T. F., Martin, J. G., and Robichaud, A. (2010). Combined forced oscillation and forced expiration measurements in mice for the assessment of airway hyperresponsiveness. Respir. Res. 11:82. doi: 10.1186/1465-9921-11-82

Tanaka, K., Ishihara, T., Azuma, A., Kudoh, S., Ebina, M., Nukiwa, T., et al. (2010). Therapeutic effect of lecithinized superoxide dismutase on bleomycin-induced pulmonary fibrosis. Am. J. Physiol. Lung Cell. Mol. Physiol. 298, L348-L360. doi: 10.1152/ajplung.00289.2009

Tanaka, K., Ishihara, T., Sugizaki, T., Kobayashi, D., Yamashita, Y., Tahara, K., et al. (2013). Mepenzolate bromide displays beneficial effects in a mouse model of chronic obstructive pulmonary disease. Nat. Commun. 4:2686. doi: 10.1038/ ncomms 3686

Tanaka, K., Kurotsu, S., Asano, T., Yamakawa, N., Kobayashi, D., Yamashita, Y., et al. (2014). Superiority of pulmonary administration of mepenzolate bromide over other routes as treatment for chronic obstructive pulmonary disease. Sci. Rep. 4:4510. doi: 10.1038/srep04510

Tanaka, K., Sato, K., Aoshiba, K., Azuma, A., and Mizushima, T. (2012). Superiority of PC-SOD to other anti-COPD drugs for elastase-induced emphysema and alteration in lung mechanics and respiratory function in mice. Am. J. Physiol. Lung Cell. Mol. Physiol. 302, L1250-L1261. doi: 10.1152/ajplung. 00019.2012
Tashkin, D. P., Celli, B., Senn, S., Burkhart, D., Kesten, S., Menjoge, S., et al. (2008). A 4-year trial of tiotropium in chronic obstructive pulmonary disease. N. Engl. J. Med. 359, 1543-1554. doi: 10.1056/NEJMoa0805800

Vestbo, J., Hurd, S. S., Agusti, A. G., Jones, P. W., Vogelmeier, C., Anzueto, A., et al. (2013). Global strategy for the diagnosis, management, and prevention of chronic obstructive pulmonary disease: GOLD executive summary. Am. J. Respir. Crit. Care Med. 187, 347-365. doi: 10.1164/rccm.201204-0596PP

Vogelmeier, C. F., Criner, G. J., Martinez, F. J., Anzueto, A., Barnes, P. J., Bourbeau, J., et al. (2017). Global strategy for the diagnosis, management, and prevention of chronic obstructive lung disease 2017 report. GOLD executive summary. Am. J. Respir. Crit. Care Med. 195, 557-582. doi: 10.1164/rccm. 201701-0218PP

Weibel, E. R. (1963). Principles and methods for the morphometric study of the lung and other organs. Lab. Invest. 12, 131-155.

Yamashita, Y., Tanaka, K., Asano, T., Yamakawa, N., Kobayashi, D., Ishihara, T., et al. (2014). Synthesis and biological comparison of enantiomers of mepenzolate bromide, a muscarinic receptor antagonist with bronchodilatory and anti-inflammatory activities. Bioorg. Med. Chem. 22, 3488-3497. doi: 10.1016/j.bmc.2014.04.029

Conflict of Interest Statement: LTT Bio-Pharma Co., Ltd. is developing MP-ADrelated compounds (such as MP) as drugs for the treatment of COPD. TM is Chairman of LTT Bio-Pharma Co., Ltd. TA and MT are employees of an endowed research division of LTT Bio-Pharma Co., Ltd.

The other authors declare that the research was conducted in the absence of any commercial or financial relationships that could be construed as a potential conflict of interest.

Copyright (C) 2018 Tanaka, Yamakawa, Yamashita, Asano, Kanda, Takafuji, Kawahara, Takenaga, Fukunishi and Mizushima. This is an open-access article distributed under the terms of the Creative Commons Attribution License (CC BY). The use, distribution or reproduction in other forums is permitted, provided the original author(s) and the copyright owner are credited and that the original publication in this journal is cited, in accordance with accepted academic practice. No use, distribution or reproduction is permitted which does not comply with these terms. 